\title{
Proposal of a CLT reinforcement of old timber floors
}

\author{
Bertrand Roensmaens ${ }^{1}$, Laurent Van Parys ${ }^{2}$, Jorge Branco $^{3}$ and Thierry Descamps ${ }^{4}$
}

\begin{abstract}
Despite the fact that, from the mechanical point of view, there is no ageing issues of timber elements when they are properly used, many old timber structures require important interventions because of changes in uses (which modifies the regulating rules for example), of material decay (misuse of timber) or possibly of a faulty design or construction. In particular, timber floors in old structures often present large deflections and most the time had been designed for a maximum load much lower than the one prescribed by contemporary rules. After an introduction about timber floors and a short review about the reinforcement technics that exist, the present paper presents a new proposal for their reinforcement. The solution developed in the present paper uses a Cross Laminated Timber (CLT) panel screwed over the existing floor, keeping a small gap between the panel and the existing joists. In this way, the new "composite" floor presents higher stiffness and the gap is used for horizontal line runs. For the design of such a "composite floor", modified Johanssen's equations (including the gap between the CLT panel and the joists) are proposed and their application on a case study is presented.
\end{abstract}

Keywords: Refurbishment, Timber floors, CLT, Self-tapping screws.

\section{Introduction}

The question of the strengthening of an existing timber floor is often asked because of changes in use or material damages [1]. The solution of adding a top concrete flange to the joists is widely used despite that the actual standards do not address clear guidelines for their design (long term behavior still remains a complex issue at the moment). From the mechanical point of view, the strengthened section behaves as a composite $\mathrm{T}$ section made of a wooden web and a concrete top flange. To ensure a composite behavior, the new concrete layer must be connected mechanically to the joists. It is worth mentioning that the shear stiffness of the connection between the wooden part and the concrete part governs the efficiency of the intervention. Since the eighties, many design for shear connectors have been studied, as for example metallic fasteners, notched shear keys (notches are made on the wooden parts), glued perforated steel plates [2]. The bending stiffness of the strengthened section is significantly increased what help to fulfill the serviceability may limit state (common weak point for timber beams under bending). The final higher in-plane stiffness also improves the lateral load resistance (useful in

\footnotetext{
${ }^{1}$ Research Assistant, Faculty of engineering, Department of structural mechanics, University of Mons, Mons, Belgium, bertrand.roensmaens@umons.ac.be

${ }^{2}$ Professor, Faculty of engineering, Department of structural mechanics, University of Mons, Mons, Belgium, laurent.vanparys@umons.ac.be

${ }^{3}$ Assistant Professor, Department of Civil Engineering, School of Engineering, University of Minho, Guimarães, Portugal jbranco(at)civil.uminho.pt

${ }^{4}$ Professor, Faculty of engineering, Department of structural mechanics, University of Mons, Mons, Belgium,

Thierry.descamps@umons.ac.be
} 
case of seismic actions for example). The fire resistance of the floor and the acoustic insulation are also much improved thanks to the concrete layer. Of course this kind of intervention on existing timber beams also present some drawbacks. When pouring the concrete slab, the water may wet or damage other timber elements. According to the residual strength of the structure as a whole (beams, walls and foundations) the large additional dead weight due to the concrete slab may be problematic. Moreover, when dealing with patrimonial timber buildings additional constrains can be added to the restorers and engineers, as for example the material compatibility or the reversibility of the intervention (without damaging the existing parts of the structure). Despite its effectiveness, the use of concrete does not enable to meet these specific constraints, particularly the reversibility. For this reason, the idea of an all wood composite $\mathrm{T}$ section beam made of a timber flange connected to main timber joists with long and inclined self-tapping screws (STS) seems to be a promising solution (dry and reversible construction) [3-4].

Another strengthening solution consists in a Cross Laminated Tim

ber (CLT) panels mechanically connected to the joists. CLT panels are made of several plies stacked and glued orthogonally, each ply being itself made by gluing and joining (end-to-end bonding) of timber boards (see Figure 1). The panels thus formed with an odd number of plies can be up to $30 \mathrm{~cm}$ thick and are mainly limited in size by transport constraints.

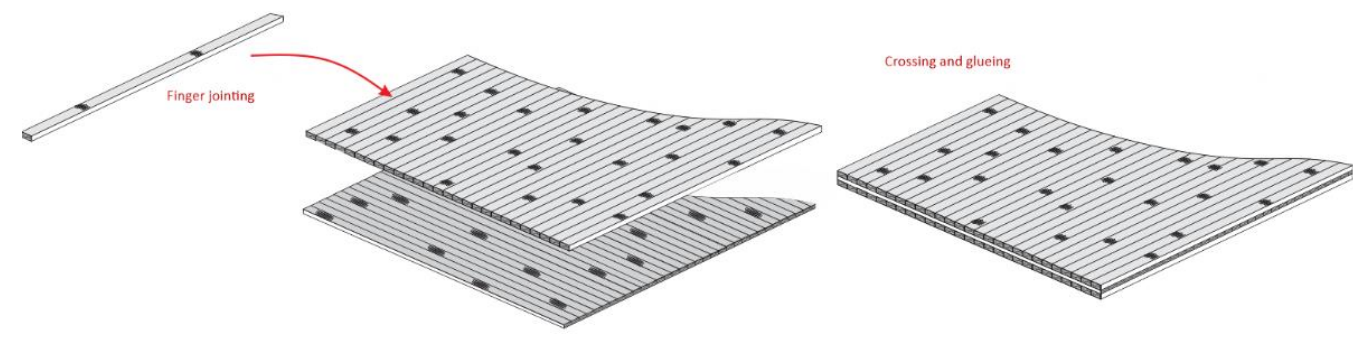

Figure 1. Cross laminated timber production process

In such a solution the concrete topping is replaced by a cross laminated timber panel. More respectful of the existing parts and lighter CLT panels provide a good stiffness (in-plane and out-of-plane) and may be used as a finish layer too. Few researchers discussed about CLT reinforcements for wooden floors in the scientific literature [5-6]. Their tests have shown that composite CLT-to-timber sections may be as efficient as composite concrete-to-timber sections [2]. Among all existing mechanical fasteners, the use of inclined STS (45 degrees screwing) seems to be the more efficient because of their low cost and the ease to use. Convinced of the interest of this method, a design model for a CLT-to-timber composite T section has been developed and discussed in [7]. This original strengthening technique consist in inserting timber blocks between the CLT panel and the joists to increase the whole stiffness (second moment of inertia). Of primary importance, the timber blocks must be resistant in compression (perpendicular to the grain) to guarantee the gap between the CLT panel and the joists. The CLT top panel is then screwed to the joists, through the timber blocks, with inclined STS. The angle of 45 degree increases the strength and the stiffness of the shear connections between the flange and the web of the composite section (see Fig.2). This paper sums up the complete analytical development that can be 
found in [7]. Additional discussion is then made for a particular geometry about the influence of the connector's stiffness on the design.

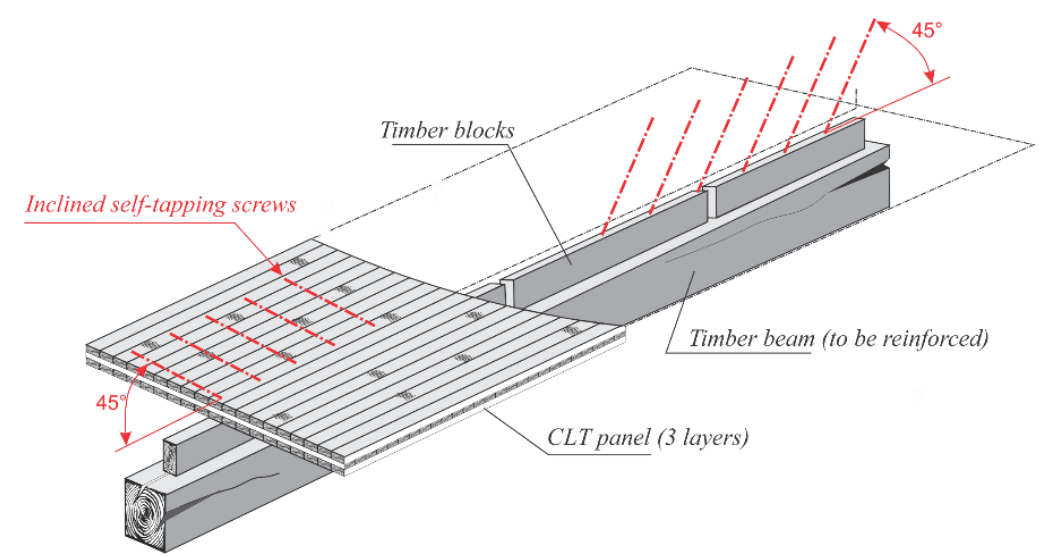

Figure 2. Strengthened timber joists with a screwed CLT panel and compression resistant timber blocks

\section{Design method}

\subsection{Gamma method}

Composite sections behaviour mainly depends on the stiffness of its connectors. This parameter, also known as the slip modulus of the connection, impacts the composite section efficiency, the stresses distribution between the different members and the whole section bending stiffness. Regarding timber-to-timber composites, Eurocode 5 (EC5) suggests to use the gamma $(\gamma)$ method [8]. This method assumes a simply supported single span beam, with a sinusoid-like distributed load and neglects the shear deflection. Moreover, it cannot be used for composite sections made of more than three layers. The bending stiffness of the whole section $(E I)_{e f}$ is calculated from the $\gamma$ parameter, which affects the Steiner part of the parallel axis theorem (see Eq. (1)). The $\gamma$ parameter varies between 0 and 1 and represents the connection efficiency between two layers.

$$
(E I)_{e f}=\sum_{i=1}^{3}\left(E_{i} I_{i}+\gamma_{i} E_{i} A_{i} a_{i}^{2}\right)
$$

Where $\mathrm{i}=1$ refers to the upper component and $\mathrm{i}=3$ refers to the lower component (see Fig. 2). $A_{i}$ is the cross section of the i-component, $I_{i}$ is the second moment of inertia of the i-component, $E_{i}$ is the modulus of elasticity of the i-component and $a_{i}$ the distance between the barycenter of the i-component and that of the composite section. The parameter $\gamma_{i}$ is defined in Eq. (2).

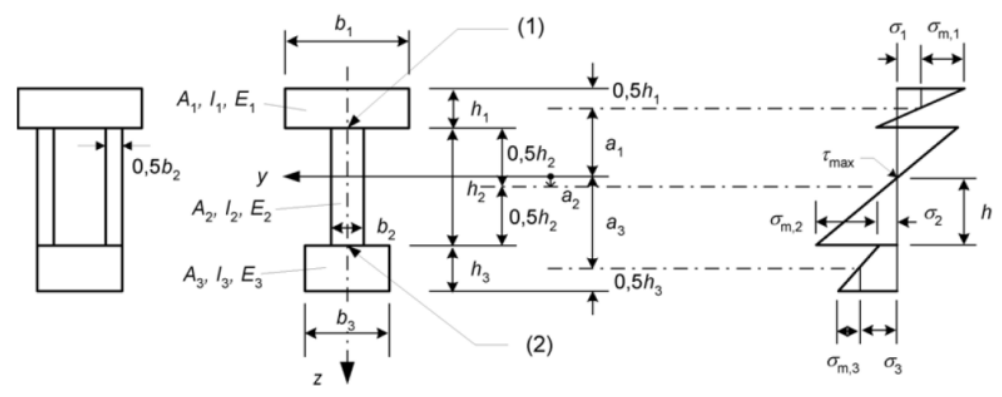

Figure 2. Cross-section (left) and distribution of bending stresses (right) [10] 


$$
\gamma_{i}=\left[1+\pi^{2} E_{i} A_{i} s_{i} /\left(K_{i} l^{2}\right)\right]^{-1} \text { for } i=1 \text { or } 3 \text { and } \gamma_{2}=1
$$

Where $K_{i}$ is the slip modulus of the fastener is, $s_{i}$ is the fastener spacing and $l$ the span of the beam. For a serviceability limit state design, the slip modulus corresponds to the $K_{\text {ser }}$ defined in EC5, while for an ultimate limit state design, the reduced value must be considered (see Eq. (3)) [8].

$$
K_{i}=\frac{2}{3} K_{\text {ser }}
$$

The $\gamma$ method is also used to homogenize the CLT panel characteristics to be used for the whole section design. For this purpose, the longitudinal layers are taken as beam elements connected together with the transverse layers. The $\gamma$ method was adapted to consider that the transverse layers rolling shear phenomenon replaces the connection slip modulus. The modified parameter $\gamma$ for a 3-layers CLT panel is defined in Eq. (4) [9]. The bending and axial stiffness are calculated respectively with Eq. (1) and Eq. (5).

$$
\begin{gathered}
\gamma_{1}=\left(1+\frac{\pi^{2} E_{1} A_{1} \bar{h}_{1}}{G_{R} b l^{2}}\right)^{-1} \text { and } \gamma_{2}=1 \\
(E A)_{C L T, e f}=\sum_{i=1}^{2} E_{i} A_{i}
\end{gathered}
$$

Where $\bar{h}_{1}$ is the thickness of the cross layer, $b$ the CLT panel width and $G_{R}$ is the rolling shear modulus of the transverse layers.

\subsection{Connector characteristics}

Because of the screwing at 45 degrees, the fasteners slip-modulus depends on their lateral and axial stiffness. Tomasi et al. [4] have proposed a calculation method to evaluate the equivalent stiffness of such connections. Assuming a linear-elastic behaviour of the screws at SLS, Eq. (6) can be written:

$$
K_{\text {ser }}=K_{\perp} \cos \alpha(\cos \alpha-\mu \sin \alpha)+K_{\|} \sin \alpha(\sin \alpha+\mu \cos \alpha)
$$

Where $K_{\perp}$ is the slip modulus for lateral loading (equal to $K_{\text {ser }}$ as defined in EC5) and $K_{\|}$is the slip modulus for withdrawal loading, $\alpha$ is the screw angle and $\mu$ is the friction coefficient between the timber elements [4]. Kevarinmäki [15] proposed Eq. (7) to determine the slip modulus for withdrawal loading $K_{\|}$.

$$
K_{\|}=\frac{1}{1 / K_{\text {ser }, a x, 1}+{ }^{1} / K_{\text {ser }, a x, 2}}
$$

Where $K_{s e r, a x, i}$ is the axial slip modulus of the threaded part anchored by a length $1_{\mathrm{i}}$ into the $i^{\text {th }}$ element.

The calculation of the load-carrying capacity of timber-to-timber connections with inclined screws is based on Bejtka and Blass's work [11] who extended the Johansen's theory (European Yield Model- EYM). According to EYM, the load-carrying capacity depends on the timber embedding strength, the fasteners bending and withdrawal capacities and the friction acting between the timber members. According to EYM, two plastic hinges per shear plane and fastener occur for failure lode (f). This failure mode is very ductile and testify of a good balance between the diameter of the screws and the timber elements thicknesses. So, it seems to be wise to 
target such a failure mode for the refurbishment of timber floors [7]. A new analytical model has been developed to consider the inner gap between the timber members.

Fig. 3 presents all parameters that affect the load-carrying capacity of the inclined screw (failure mode (f)) screwed with an inner gap. The equilibrium equations lead to the load-carrying capacity for failure mode (f) (see Eq. (8)), which is the generalized formulation of Bejtka's equation (gap and compression resistant interlayer) [7].

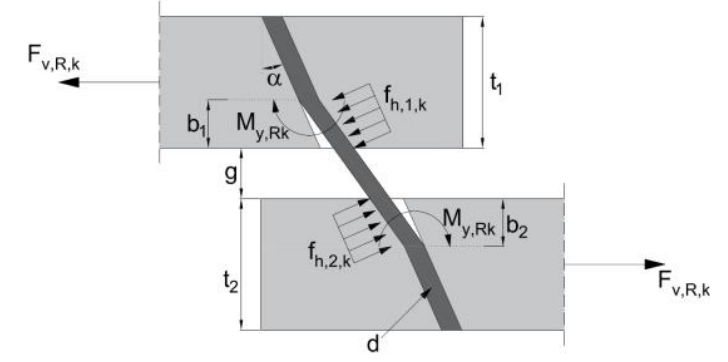

Figure 3. Equilibrium of inclined screw with inner gap between timber elements. Failure mode (f)

$$
F_{v, R k}=F_{a x}(\sin \alpha+\mu \cos \alpha)+(1-\mu \tan \alpha) f_{h, 1, k} d \frac{\beta}{\beta+1}\left[\sqrt{g^{2}+\frac{4 M_{y, R k}(\cos \alpha)^{2}}{f_{h, 1, k} d} \frac{\beta+1}{\beta}}-g\right]
$$

Where $F_{a x}$ is defined in Eq. (9), $f_{h, i, k}$ is the embedment strength of the $i^{\text {th }}$ element, $g$ is the gap thickness, $d$ is the screw diameter, $\beta$ is defined in Eq. (10), and $M_{y, R k}$ is the screw yield moment.

$$
F_{a x}=\min \left(F_{a x, R k, 1}, F_{a x, R k, 2}\right)
$$

Where $F_{a x, R k, i}$ is the axial withdrawal capacity of the screw into the $i^{\text {th }}$ element.

$$
\beta=\frac{f_{h, 2, k}}{f_{h, 1, k}}
$$

\section{Application}

\subsection{Strengthening of an existing timber floor}

The design method was applied to an existing timber floor made of joists (section 140x140 $\mathrm{mm}^{2}$ ) with a spacing of $500 \mathrm{~mm}$ and a span of $4200 \mathrm{~mm}$. The proposed strengthening solution is composed by a 3-layers CLT panel, compression resistant timber blocks and STS. The CLT panel is $78 \mathrm{~mm}$ thick and the compression resistant timber block section is $50 \times 50 \mathrm{~mm}^{2}$. The $9 \mathrm{~mm}$-diameter screws are $350 \mathrm{~mm}$ long and are screwed with a $45^{\circ}$ angle and a spacing of $170 \mathrm{~mm}$. The mechanical properties of the panel and the STS are given in [12] and [13] respectively. To undertake the calculation, it was necessary to make reasonable assumptions. Firstly, because of the lack of normative value about the CLT effective width, table 9.1 of EC5 was used considering the limitations applied to OSB panels [8]. Secondly, the total screws withdrawal capacity was used instead of the Bejtka's withdrawal capacity parameter [11] and the effective diameter defined in EC5 was used [8]. Thirdly, the values of the friction coefficient $(\mu=0.25)$ and the connection stiffness are assumed to be the same as for 
connections without gaps. These values constituting an upper bound of the real value, ongoing tests will help to find more suitable formulations for them. Finally, the failure mode for a connection without gaps was investigated using the Bejtka's equations for inclined screws (see Table 1). The failure mode is the one with the lowest load-carrying capacity (failure mode (f)). It was assumed then this failure mode would be the same for the connection with a $50 \mathrm{~mm}$ gap [7].

Table 2 presents, for the initial timber floor and its refurbishment, the effective stiffness of the whole section, the calculated stress and the corresponding limit values. The joist maximum normal stress ratio between the strengthened floor and the initial floor reaches $30.6 \%$; while the bending stiffness ratio is $489 \%$. These ratios show the interest of the new refurbishment technique. One may notice that the joist shear stress is equal between the two configurations because only the joists allow the support on the wall.

Table 1. Bejtka's equation results for each failure mode considering a connection without gaps

\begin{tabular}{|c|c|}
\hline Failure mode & Load-carrying capacity $\mathrm{F}_{\mathrm{v}, \mathrm{Rk}}[\mathrm{N}]$ \\
\hline (a) embedding of CLT member & 18288 \\
\hline (b) embedding of timber member & 30567 \\
\hline (c) embedding of both timber and CLT members with rotation of the fastener & 18399 \\
\hline (d) embedding of CLT member and fastener plastic hinge in timber member & 14928 \\
\hline (e) embedding of timber member and fastener plastic hinge in CLT member & 18399 \\
\hline (f) fastener plastic hinge in both timber and CLT members & $\mathbf{1 2 7 1 3}$ \\
\hline
\end{tabular}

Table 2. Comparison between the initial timber floor and the refurbishment. (Dead load $=1 \mathrm{kN} / \mathrm{m}^{2}-$ live load $=5 \mathrm{kN} / \mathrm{m}^{2}-\mathrm{k} \bmod =0.8$ $\left.-\gamma_{\text {timber }}=1.3-\gamma_{\text {CLT }}=1.25-\gamma_{\text {connection }}=1.3\right)$

\begin{tabular}{|c|c|c|c|c|c|c|}
\hline & \multicolumn{2}{|c|}{ Initial floor without strengthening } & \multicolumn{3}{c|}{ Refurbishment of floor with a gap of 50 mm } \\
\cline { 2 - 7 } & Max. value & Calculated value & Ratio [\%] & Max. value & Calculated value & Ratio [\%] \\
\hline$(\mathrm{El})_{\mathrm{ef}, \mathrm{ELU}}\left[\mathrm{Nmm}^{2}\right]$ & - & $3.201 \times 1011$ & - & - & $1.565 \times 1012$ & - \\
\hline$\sigma_{\mathrm{CLT}, \max }\left[\mathrm{N} / \mathrm{mm}^{2}\right]$ & - & - & - & 15.36 & 5.6 & 36.5 \\
\hline$\sigma_{\text {joist,max }}\left[\mathrm{N} / \mathrm{mm}^{2}\right]$ & 18.46 & 21.33 & 116 & -18.46 & -6.53 & 35.4 \\
\hline$\tau_{\text {joist,max }}\left[\mathrm{N} / \mathrm{mm}^{2}\right]$ & 1.85 & 1.06 & 57.5 & 1.85 & 1.06 & 57.5 \\
\hline $\mathrm{b}_{1}[\mathrm{~mm}]$ & - & - & - & 19 & 2.2 & 11.6 \\
\hline $\mathrm{V}_{\text {connection }}[\mathrm{kN} / \mathrm{screw}]$ & - & - & - & 7.08 & 6.86 & 96.9 \\
\hline
\end{tabular}

\subsection{Impact of the slip modulus value}

As explained above, the connection slip modulus is of major importance for the composite section efficiency. Indeed, it impacts the effective bending stiffness of the whole section and then the stress distribution between the connected members. The previous application was calculated under the assumption that the connection stiffness is the same as for connections without gaps. Fig. 4 and Fig. 5 show the evolution of different section characteristics depending on the connectors slip modulus factor for two gap values (50 $\mathrm{mm}$ and $75 \mathrm{~mm})$. The slip modulus factor is defined as the ratio between the actual slip modulus and the slip modulus considering no gap between the connected elements. The calculations are made with the same screws length for the two gap widths. The bending stiffness drops significantly with the slip modulus factor. This trend is more significant for a greater gap. Regarding the normal stress at top of panel and base of joist, a bending stiffness decrease leads to a stress rise. For a $50 \mathrm{~mm}$-gap, the bending stiffness obtained considering no connection between the members $($ ratio $=0 \%$ ) reaches $31 \%$ of those calculated with a slip modulus factor of $100 \%$. This results in a $169 \%$ and $216 \%$ increase of top of panel and base of joist stress, respectively. The greater differences in maximum stresses 
appears with small slip modulus values (slip modulus factor between 0 and $30 \%$ ). Concerning the $75 \mathrm{~mm}$-gap, the ratios become $26 \%$ for the bending stiffness and $192 \%$ and $248 \%$ for the top of panel and base of joist stress, respectively. The values obtained for a slip modulus factor of $0 \%$ are the same whatever the gap width. Physically, this means that there is no connection between the two elements. Then, they support the load independently from each other. Although considering no connection seems very unfavorable, this example emphasizes the need to determine the exact values of the connection slip modulus.
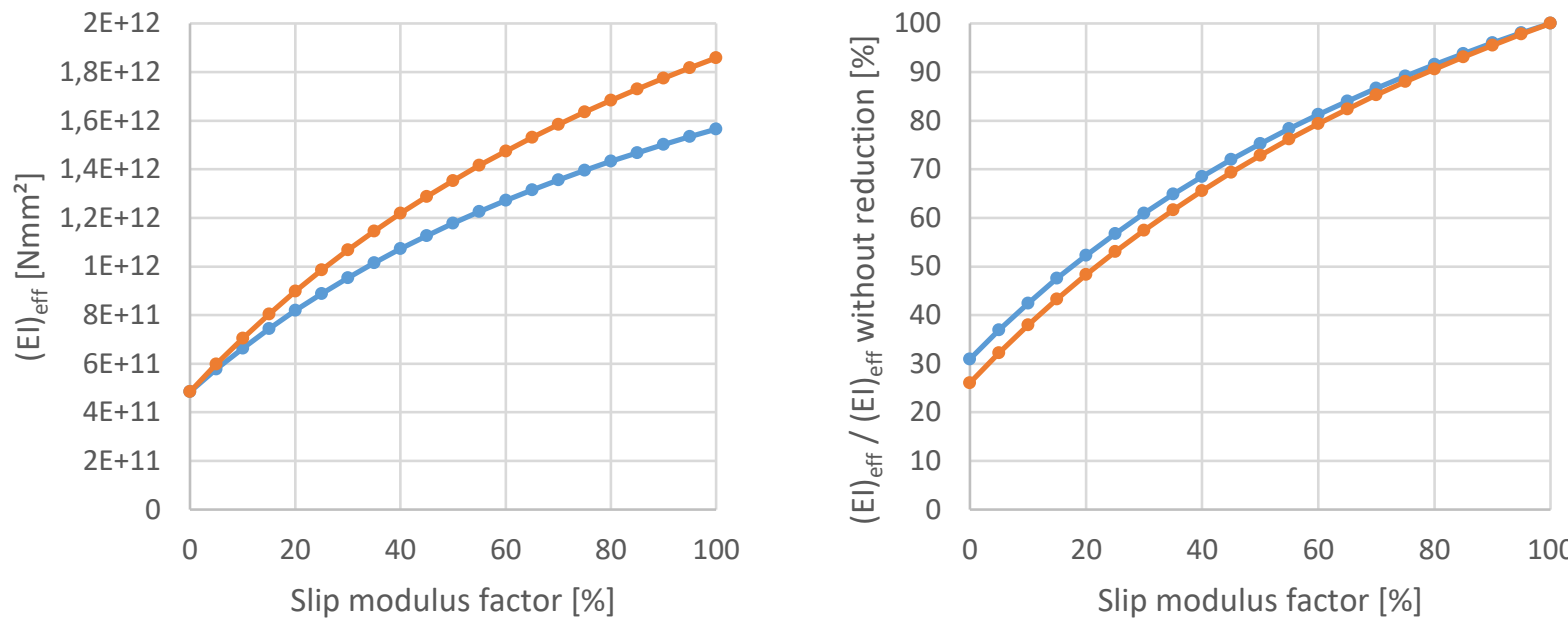

$\multimap$ Gap $=50 \mathrm{~mm} \quad \longrightarrow$ Gap $=75 \mathrm{~mm}$

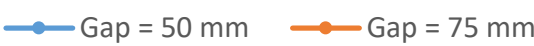

Figure 4. Evolution of effective bending stiffness for different slip modulus factors and for two gap values (50 $\mathrm{mm}$ and $75 \mathrm{~mm}$ )
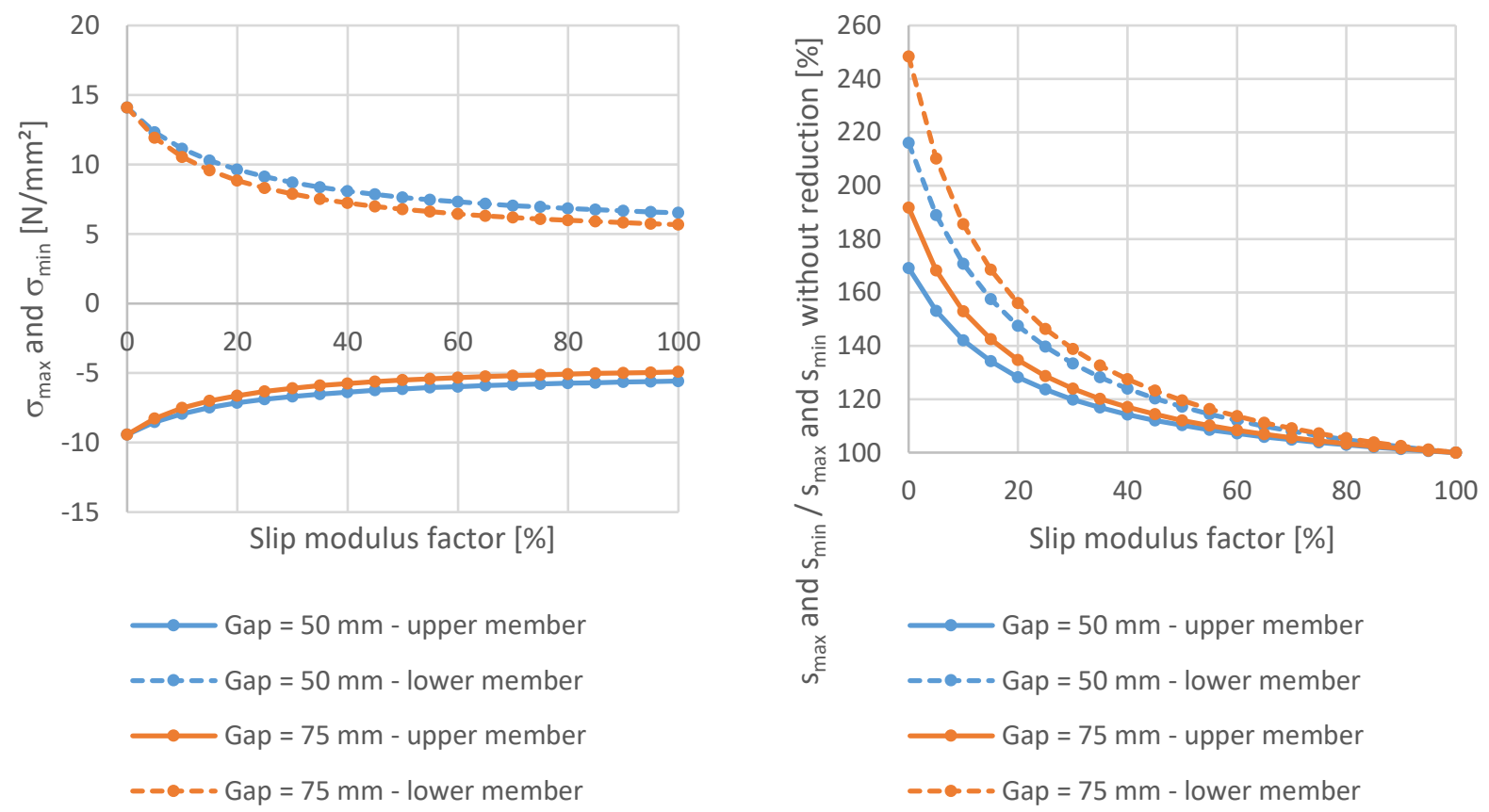

Figure 5. Evolution of the maximal and minimal normal stress for different slip modulus factors and for two gap values (50 mm and $75 \mathrm{~mm})$ 


\section{Conclusion}

The concept of strengthening an existing timber floor with a CLT panel and an inner gap between them was presented. The gap width remains constant thanks to compression resistant timber blocks. Those blocks affect the global behavior of the section by increasing the second moment of inertia. The connection between the CLT panel and the existing structure is made with $45^{\circ}$ inclined self-tapping screws. To consider the effect of the inner gap on the screws load-carrying capacity, an analytical model was presented. This model stems from Bejtka's equations for the calculation of inclined fasteners.

The calculation method was discussed through an example. The $\gamma$ method is used, firstly to homogenize the CLT panel and secondly to determine the bending stiffness and the stress in the whole composite section. The example showed the interest of the technique under reasonable assumptions, including that on using the slip modulus of a connection without gaps, which was discussed trough two comparative examples. This showed the interest to precisely determine the exact slip modulus of the connection. Experiments are in progress to compare their results of the theoretical study results and to emphasize the real behaviour of such connections in terms of stiffness, load-carrying capacity, friction coefficient and failure modes.

\section{References}

[1] Kouroussis, G., Ben Fekih, L., and Descamps T. (2017) Assessment of timber element mechanical properties using experimental modal analysis. Construction \& Building Materials, 134:254-261. doi: 10.1016/j.combuildmat.2016.12.081

[2] Gubana, A. (2015) State-of-the-art report on high reversible timber to timber strengthening interventions on wooden floors. Construction \& Building Materials, 97:25-33. doi: 10.1016/j.combuildmat.2015.06.035

[3] Blaß, H.J., and Bejtka, I. (2001) Screws with continuous threads in timber connections. In: Aicher, Reinhardt (eds) Proceedings of International RILEM Symposium on Joints in Timber Structures, Stuttgart, Germany, pp 193-201.

[4] Tomasi, R., Crosatti, A., and Piazza, M. (2010) Theoretical and experimental analysis of timber-to-timber joints connected with inclined screws. Construction \& Building Materials, 24:1560-1571. doi: 10.1016/j.combuildmat.2010.03.007

[5] Riggio, M., Tomasi, R., and Piazza M. (2014) Refurbishment of a traditional timber floor with a reversible technique: importance of the investigation campaign for design and control of the intervention. International Journal of Architectural Heritage, 8(1):74-93. doi : 10.1080/15583058.2012.670364

[6] Gubana, A. (2010) Experimental tests on timber-to-cross lam composite section beams. In: Ceccotti (ed) Proceedings of 11th World Conference on Timber Engineering WCTE 2010, Riva del Garda, TN, Italy.

[7] Roensmaens B., Van Parys L., Carpentier O. and Descamps T. (2018) Refurbishment of existing timber floors with screwed CLT panels, International Journal of Architectural Heritage. doi: 10.1080/15583058.2018.1442522

[8] European committee for standardization (CEN) (2005) EN 1995-1-1:2004. Eurocode 5 Design of timber structures - Part 1-1 General - Common rules and rules for buildings + ANB (2006) and A1 (2008). Bruxelles.

[9] Gagnon, S., and Pirvu, C. (2011) CLT Handbook. FPInnovations, Canada.

[10] Kevarinmäki, A. 2002. Joints with inclined screws. In Proceedings of meeting 35 of the Working Commission W18 - Timber Structures, CIB, Kyoto, Japan, paper CIB-W18/35-7-3.

[11] Bejtka, I., and Blaß, H. J. 2002. Joints with inclined screws. In Proceedings of meeting 35 of the Working Commission W18 - Timber Structures, CIB, Kyoto, Japan, paper CIB-W18/35-7-4.

[12] DTA 3+5/12-731 (2014) Panneaux KLH. Scientific and Technical Center for Building (CSTB)

[13]ETA-12/0062 (2012) SFS self-tapping screws WR. Austrian Institute of Construction Engineering (OIB) 